\title{
EFFICACY, SAFETY AND TOLERABILITY OF SILDENAFIL IN BRAZILIAN HYPERTENSIVE PATIENTS ON MULTIPLE ANTIHYPERTENSIVE DRUGS
}

\author{
DENILSON C. ALBUQUERQUE, LINEU J. MIZIARA, JOSE F. K. SARAIVA, ULISSES S. \\ RODRIGUES, ARTUR B. RIBEIRO, MAURICIO WAJNGARTEN
}

Department of Cardiology (DCA), State University of Rio de Janeiro, Department of Cardiology (LJM), Federal University of Uberlandia, Minas Gerais, Department of Cardiology (JFKS), Pontifical Catholic University, Campinas, Sao Paulo, Department of General Practice (USR), Salgado Filho Hospital, Rio de Janeiro, Department of Nephrology (ABR), Federal University of Sao Paulo, UNIFESP, CardioGeriatry Service (MW), Institute of Heart, INCOR, Sao Paulo, Brazil

\begin{abstract}
Objective: To evaluate the efficacy, safety and tolerability of sildenafil among Brazilian patients with hypertension treated with combinations of anti-hypertensive drugs.

Materials and Methods: One hundred twenty hypertensive men aged 30 to 81 years old under treatment with 2 or more anti-hypertensive drugs and with erectile dysfunction (ED) lasting for at least 6 months were enrolled at 7 research centers in Brazil. Patients were randomized to receive treatment with either sildenafil or placebo taken 1 hour before sexual intercourse (initial dose of 50 $\mathrm{mg}$, adjusted to $25 \mathrm{mg}$ or $100 \mathrm{mg}$ according to efficacy and toxicity). During the following 8 weeks, patients were evaluated regarding vital signs, adverse events, therapeutic efficacy, satisfaction with treatment and use of concurrent medications.

Results: The primary evaluation of efficacy, which was based on responses to questions 3 and 4 of the International Index of Erectile Function, showed significant differences regarding treatment with sildenafil ( $p=0.0002$ and $p<0.0001$, respectively). In the assessment of global efficacy, $87 \%$ of the patients treated with sildenafil reported improved erections, as compared with $37 \%$ of patients given placebos $(\mathrm{p}<0.0001)$. The other secondary evaluations supported the results favoring sildenafil. The most frequent adverse events among patients treated with sildenafil were headaches $(11.4 \%)$, vasodilation $(11.4 \%)$ and dyspepsia $(6.5 \%)$. There were no significant changes in blood pressure measurements in both groups.

Conclusion: Sildenafil is efficacious and safe for the treatment of hypertensive patients with ED who receive concurrent combinations of anti-hypertensive drugs.
\end{abstract}

Key words: erectile dysfunction; sildenafil; hypertension; anti-hypertensive drugs

Int Braz J Urol. 2005; 31: 342-55

\section{INTRODUCTION}

Erectile dysfunction (ED) is defined as the persistent inability to achieve and/or maintain an erection sufficient for sexual intercourse (1). ED is multi- factorial and associated with several risk factors, such as hypertension, diabetes mellitus, peripheral vascular and coronary artery disease, neurological diseases, alcohol abuse, smoking, depression and others. The prevalence of ED varies according to age and the pres- 
ence of co-morbidities. In addition, the proportion of men that report ED varies from country to country (2). According to a recent survey, approximately $46 \%$ of Brazilian men report some degree of ED, which may lead to an impaired quality of life in many cases (3).

Hypertension is a public health problem of global proportions. Although national estimates are scarce and may not represent the overall population, regional surveys have shown that the prevalence of hypertension in Brazil varies from $22 \%$ to $44 \%$ (4). Hypertension is frequently accompanied by other medical problems, including dyslipidemias, diabetes mellitus, heart disease and smoking, which may also cause or aggravate ED. It has recently been estimated that $42 \%$ of American men with ED are also hypertensive (5). Men with hypertension have an up to fourfold increase in the risk of developing ED, especially with the use of drugs such as beta-blockers and thiazides, which may have ED as side effects $(6,7)$. Among patients with hypertension, ED may decrease the quality of life, self-esteem and the relationship with a partner. Although the exact pathogenesis of ED in men with hypertension has not been fully elucidated, in many cases psychogenic factors accompany the organic abnormalities that are secondary to hypertension, thus contributing to the aggravation of ED.

Several clinical trials have demonstrated the efficacy of sildenafil in the treatment of ED with various causes (8-10). Most adverse events reported in the clinical studies of sildenafil, including headaches, flushing and nasal congestion are thought to be related to the vasodilating properties of the drug. The incidence of these adverse events increases with higher doses of sildenafil. The possibility of potentiating the effect of anti-hypertensive medications has been a major concern regarding the use of sildenafil for the treatment of hypertensive men with ED. Preliminary clinical trials have not shown clinically significant changes in blood pressure levels among patients who were treated with sildenafil and concurrent anti-hypertensive medications. There is, however, little information in the literature regarding the use of regimens of multiple anti-hypertensive drugs (11).
The objective of the present study is to investigate the efficacy, safety and tolerability of sildenafil in outpatients with hypertension and who were on treatment with combinations of anti-hypertensive drugs.

\section{MATERIALS AND METHODS}

\section{Inclusion and Exclusion Criteria}

Eligible patients were men aged 18 years or older who had had a stable sexual relationship for the previous 6 months, with a clinical diagnosis of ED of at least 6 months' duration, and with hypertension that was being treated with at least 2 drugs from any of the following classes: diuretics, alpha-blockers, beta-blockers, angiotensin converting enzyme (ACE) inhibitors, or calcium-channel blockers. To be eligible for the study, patients also had to have a score $\leq 25$ in the erectile function domain of the International Index of Erectile Function (IIEF) (12). Exclusion criteria were any of the following: concurrent treatment with nitrates, the presence of any genital deformity or sexual disturbance that precluded sexual intercourse, the use of any form of treatment for ED within the 4 weeks preceding enrollment, alcohol or drug abuse, the presence of retinitis pigmentosa, degenerative retinopathy or any major medical condition, and the inability to fill in the event log or comply with the study. The protocol was reviewed and approved by the Institutional Review Boards of all participating centers, and all patients enrolled in the study provided written informed consent.

\section{Study Design}

Candidate patients were initially evaluated through a complete history, including sexual function, and a complete physical examination, including the determination of blood pressure (BP) and heart rate in sitting and in supine position. On the initial visit, patients also underwent laboratory exams (complete blood count, sodium, potassium, creatinine, glucose, transaminases, cholesterol, triglycerides, prolactin, testosterone and urinalysis) and electrocardiogram. Four weeks later, eligible patients were randomized to receive treatment with sildenafil or placebo. Randomization was achieved through computer- 
generated blocks of random numbers. Sildenafil and placebo tablets had the same appearance and were dispensed in identical containers. Patients were instructed to take the study drug 1 hour before intended sexual intercourse and not more than once daily. Based on previous studies, the initial dose of sildenafil was $50 \mathrm{mg}$. In subsequent visits, this dose could be increased to $100 \mathrm{mg}$ or decreased to $25 \mathrm{mg}$ depending on efficacy and tolerability. Patients were evaluated 2, 4 and 8 weeks after randomization. Vital signs, the use of concurrent medications, compliance and the results obtained with the study treatment were assessed at each visit. Treatment could last for a maximum of 8 weeks.

\section{Assessment of Efficacy, Safety and Tolerability}

Patients were instructed to record in the event $\log$ the amount of medication taken and the results achieved with treatment. The intent-to-treat (ITT) population was defined as those patients who took at least one dose of a study drug and recorded at least one efficacy measurement during treatment. In addition, the sample of patients who could be evaluated was comprised of those with complete follow up and responses to the IIEF questions during the study. The assessment of efficacy was done in these patients. The primary efficacy parameter was the difference in pretreatment and post-treatment scores for questions 3 and 4 of the IIEF. Secondary measures of treatment efficacy were the difference in pre-treatment and posttreatment scores for other questions and for the domains of the IIEF, patients' responses to the Erectile Dysfunction Inventory of Treatment Satisfaction questionnaire (EDITS) (13) and the assessment of global efficacy, and the proportion of successful attempts at sexual intercourse. Patients were instructed to register all symptoms experienced during the study, and also to report promptly in the event of a serious adverse effect. All cases of treatment interruption were recorded, regardless of the cause leading to discontinuation.

\section{Statistical Analysis}

Based on the assumption that the minimum clinically relevant treatment difference between sildenafil (combined dose groups) and placebo with regards to IIEF scores (questions 3 and 4 ) is 0.75 and that the common variance is 2.3 , sample sizes of at least 65 subjects per treatment group (sildenafil and placebo) were required to detect the specified difference between the two treatment groups, with a power of $80 \%$ and a type I error rate of 5\%. The comparisons between groups regarding the change from baseline in IIEF questions were assessed with unpaired Student's t test. Mann-Whitney tests were applied to compare the two groups regarding each question of the EDITS questionnaire. Comparisons between sildenafil and placebo groups regarding the behavior of BP during the study, were done using analysis of variance for repeated measurements. Multiple comparisons were based on Wald's statistics. The differences between proportions of satisfactory responses in the assessment of global efficacy were compared using the Pearson's Chi-square test. The proportion of successful attempts at intercourse was compared between the two groups using a generalized estimation equation model assuming a uniform structure for the correlation. All hypothesis testing considered a $\mathrm{p}$ value $\leq 0.05$ as statistically significant.

\section{RESULTS}

\section{Patient Characteristics}

One hundred and fifty-three patients were recruited from seven research centers in Brazil. One hundred and twenty patients took at least on dose of the study drug; 87 of them completed the 8 weeks of treatment and could be evaluated. Table- 1 shows the main demographic and clinical characteristics of the ITT sample at baseline. There were no statistically significant differences in any of these characteristics between groups. The age of the patients varied between 30 and 81 years, the time since the start of ED varied from 0.6 and 30 years, and the time since hypertension was diagnosed varied from 2 to 52 months. The etiology of erectile dysfunction, which was determined on clinical grounds, was similar between both groups, and approximately two-thirds of patients had ED of mixed etiology.

The anti-hypertensive medication most frequently utilized by the patients in both groups was a 
Table 1 - Patient characteristics at baseline (intent-to-treat sample, $N=120$ )

\begin{tabular}{lll}
\hline Variable & Sildenafil, $\mathbf{N}=\mathbf{6 1}(\boldsymbol{\%})$ & Placebo, $\mathbf{N}=\mathbf{5 9}(\boldsymbol{\%})$ \\
\hline Age, years & & 60.6 \\
Mean & 59.4 & 30 to 81 \\
Range & 35 to 79 & $15(25.4)$ \\
Smoking & $13(21.3)$ & $30(50.2)$ \\
Alcohol use & $30(49.2)$ & \\
Duration of erectile dysfunction, years & & 2.3 \\
Median & 2.0 & 0.6 to 30 \\
Range & 0.6 to 24 & $11(18.6)$ \\
Etiology of erectile dysfunction & $11(18)$ & $7(11.9)$ \\
Organic & $9(14.8)$ & $41(69.5)$ \\
Psychogenic & $41(67.2)$ & $11.2 \pm 9.6$ \\
Mixed & $11.7 \pm 9.0$ & 2 to 52 \\
Duration of hypertension, months & 2 to 43 & \\
$\quad$ Mean \pm standard deviation & Range &
\end{tabular}

diuretic, followed by ACE inhibitors, calcium-channel blockers, beta-blockers and alpha-blockers (Figure-1). Patients remained on the same anti-hypertensive regimen for the whole study period. Eighty-seven patients (44 in the sildenafil group and 43 in the placebo group) took 2 anti-hypertensive drugs, 27 patients (15 in the sildenafil group and 12 in the placebo group) took 3 anti-hypertensive drugs, and 6 (2

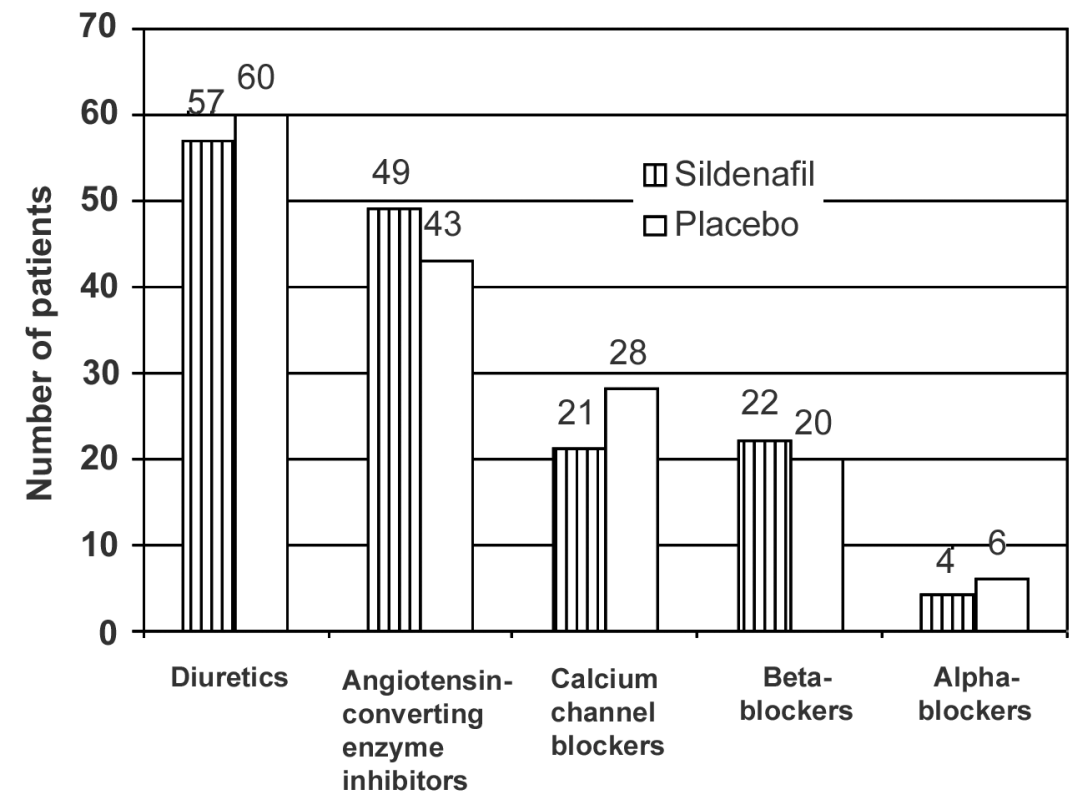

Figure 1 - Anti-hypertensive drugs in both groups. 
in the sildenafil group and 4 in the placebo group) took 4 or more anti-hypertensive drugs. The most frequent co-morbidities were dyslipidemias, diabetes mellitus and ischemic heart disease. The baseline electrocardiogram was considered normal in $43 \%$ of the patients; the most frequent abnormalities in the remaining cases were arrhythmias, aberrant electric conduction and ventricular hypertrophy. There were no significant changes in the electrocardiograph readings between both groups.

\section{Therapeutic Efficacy}

At the conclusion of the study, 33 patients (54.1\%) were taking $50 \mathrm{mg}$ of sildenafil, 24 (39.3\%) were taking $100 \mathrm{mg}$, and 4 patients $(6.6 \%)$ were taking $25 \mathrm{mg}$. For patients taking the placebo, the proportions were $20.3 \%, 74.6 \%$ and $5.1 \%$ respectively. Compared with patients that took the placebo, patients treated with sildenafil had more ability to achieve an erection sufficient for sexual intercourse $(\mathrm{p}=0.0002)$, and also to maintain erections during the sexual intercourse period $(p<0.0001)$ (Table-2). Similarly, the differences between the scores for other IIEF questions before and after treatment, favored the group treated with sildenafil. As shown in Table-3, with the exception of questions 6,9 and 11 of the IIEF (frequency of intercourse, ejaculation and desire), all other differences achieved statistical significance. When the questions were grouped and the differences were analyzed according to the IIEF domain, there was a significant difference favoring sildenafil in four of the five IIEF domains; the only domain for which no such difference was evident was the sexual desire domain (Figure-2).

The secondary efficacy analyses confirmed the superiority of sildenafil over placebo for the treatment of ED in patients who are on multiple anti-hypertensive drugs. There were significant differences favoring sildenafil in all 11 questions of the EDITS questionnaire, and all statistical comparisons between the two groups yielded $p$ values of $<0.007$. The assessment of global efficacy showed that $87 \%$ of the patients treated with sildenafil reported improvement in their erections; this same proportion was $37 \%$ among patients that took the placebo $(\mathrm{p}<0.0001)$. The analysis of event logs demonstrated statistically significant differences between the two groups in the proportions of successful attempts at sexual intercourse. Among patients treated with sildenafil, successful attempts were reported in 54\%, 61\% and $73 \%$ of the times after 2, 4 and 8 weeks of treatment. Among patients that took the placebo, these same proportions were $13 \%, 20 \%$ and $29 \%$ ( $p<0.0001$ for the comparison between groups at each time point).

\section{Safety and Tolerability}

\section{Adverse Events}

The analysis of safety and tolerability was based on the ITT sample of 120 patients. Twenty-

Table 2 - Mean \pm standard deviation scores on questions 3 and 4 of International Index of Erectile Function (IIFE). Evaluable sample, $N=87$.

\begin{tabular}{|c|c|c|c|c|c|c|c|}
\hline \multirow[b]{2}{*}{$\begin{array}{l}\text { IIFE } \\
\text { Questions }\end{array}$} & \multicolumn{3}{|c|}{ Sildenafil ( $N=46$ ) } & \multicolumn{3}{|c|}{ Placebo $(\mathrm{N}=41)$} & \multirow[b]{2}{*}{$\mathbf{P}$} \\
\hline & $\begin{array}{c}\text { Pre- } \\
\text { treatment }\end{array}$ & $\begin{array}{l}\text { Post- } \\
\text { treatment }\end{array}$ & Difference & $\begin{array}{c}\text { Pre- } \\
\text { treatment }\end{array}$ & $\begin{array}{l}\text { Post- } \\
\text { treatment }\end{array}$ & Difference & \\
\hline $\begin{array}{l}\text { 3) Penetration } \\
\text { Ability }\end{array}$ & $2.15 \pm 1.37$ & $4.04 \pm 1.33$ & $1.89 \pm 1.49$ & $2.05 \pm 1.60$ & $2.61 \pm 1.63$ & $0.56 \pm 1.75$ & 0.0002 \\
\hline $\begin{array}{l}\text { 4) Maintenance } \\
\text { Frequency }\end{array}$ & $2.04 \pm 1.41$ & $3.96 \pm 1.40$ & $1.91 \pm 1.71$ & $1.95 \pm 1.56$ & $2.24 \pm 1.59$ & $0.29 \pm 1.90$ & $<0.0001$ \\
\hline
\end{tabular}

$P$ values refer to comparisons between differences. IIFE, International Index of Erectile Function. 
Table $3-$ Mean \pm standard deviation scores on questions 1, 2 and 5 to 15 of International Index of Erectile Function (IIFE). Evaluable sample, $N=87$.

\section{Sildenafil $(\mathbf{N}=\mathbf{4 6})$}

IIFE

Questions

1) Erection

Frequency

2) Erection

Firmness

5) Maintenance

Ability

6) Intercourse

Frequency

7) Intercourse

Satisfaction

8) Intercourse

Enjoyment

9) Ejaculation Frequency

10) Orgasm Frequency

11) Desire Frequency

12) Desire Level

13) Overall Satisfaction

14) Relationship Satisfaction

15) Erection Confidence

Pre- Posttreatment treatment

$2.26 \pm 1.44$

$4.22 \pm 1.25$

$1.98 \pm 1.34$

$4.09 \pm 1.26$

$2.09 \pm 1.26$

$4.20 \pm 1.19$

$2.35 \pm 1.39$

$2.09 \pm 1.36$

$2.04 \pm 1.09 \quad 3.80 \pm 1.00$

$3.20 \pm 1.85$

$4.24 \pm 1.21$

$2.89 \pm 1.66$

$4.28 \pm 1.17$

$3.41 \pm 1.13$

$4.04 \pm 0.97$

$2.98 \pm 0.72$

$3.52 \pm 0.91$

$2.11 \pm 1.18$

$2.52 \pm 1.26$

$2.41 \pm 0.91$
$2.11 \pm 1.39$

$1.80 \pm 1.36$

$2.27 \pm 1.50$

$0.46 \pm 1.43<0.0001$

Pre-

Placebo $(\mathrm{N}=41)$

Difference

treatment

$2.00 \pm 1.58$

$2.59 \pm 1.50$

$0.59 \pm 1.28<0.0001$

$2.11 \pm 1.37$

$2.22 \pm 1.26$

$2.63 \pm 1.51$

$0.41 \pm 1.86$

$<0.0001$

$4.15 \pm 1.28 \quad 1.80 \pm 1.51$

$2.05 \pm 1.38$

$3.44 \pm 1.38$

$1.39 \pm 2.10$

$=0.2902$

$4.15 \pm 1.23 \quad 2.07 \pm 1.50$

$1.76 \pm 1.30$

$2.34 \pm 1.42$

$0.59 \pm 1.84$

$<0.0001$

$1.76 \pm 1.21$

$1.78 \pm 1.27$

$2.37 \pm 1.26$

$0.59 \pm 1.60<0.0001$

$1.04 \pm 1.76$

$2.39 \pm 1.84$

$2.93 \pm 1.60$

$0.54 \pm 1.89=0.3206$

$1.39 \pm 1.74$

$2.51 \pm 1.78$

$2.95 \pm 1.63$

$0.44 \pm 2.03=0.0129$

$0.63 \pm 1.39$

$3.39 \pm 1.45$

$3.83 \pm 1.14$

$0.44 \pm 1.34=0.2966$

$0.51 \pm 0.92$

$3.07 \pm 1.03$

$3.17 \pm 0.83$

$0.10 \pm 1.09=0.0085$

$4.15 \pm 1.23 \quad 2.04 \pm 1.50$

$2.15 \pm 1.06$

$2.32 \pm 1.31$

$0.17 \pm 1.26<0.0001$

$4.09 \pm 1.09 \quad 1.57 \pm 1.44$

$2.22 \pm 1.11$

$2.71 \pm 1.44$

$0.49 \pm 1.36=0.0006$

$3.63 \pm 1.04 \quad 1.22 \pm 0.99$

$2.24 \pm 1.02$

$2.41 \pm 1.09$

$0.17 \pm 1.20$

$<0.0001$

$P$ values refer to comparisons between differences. 


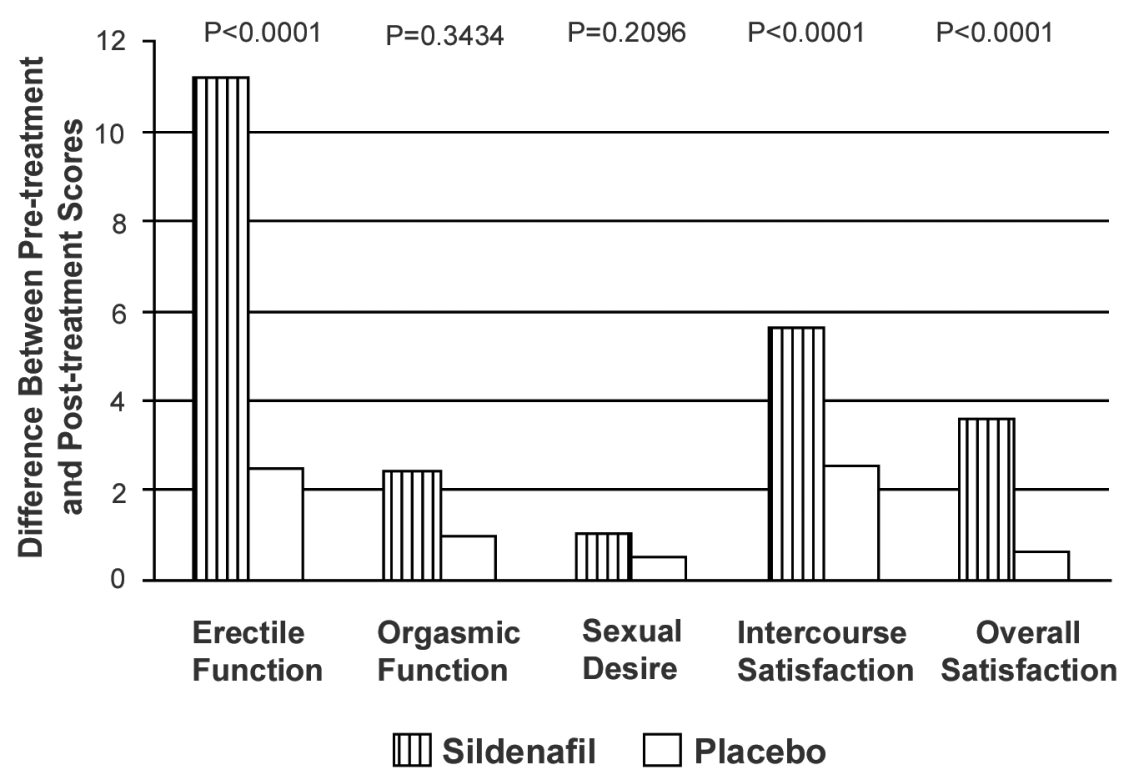

Figure 2 - Comparison between the efficacy of sildenafil and placebo, assessed by domains of the International Index of Erectile Function (evaluable sample, $N=87$ ). P values refer to the difference between sildenafil and placebo in pretreatment and post-treatment scores for each domain.

two patients had their treatment with the study drug discontinued. Only 3 patients ( 1 treated with sildenafil and 2 with placebo) had their treatments interrupted due to adverse events. In all other cases, discontinuation of treatment was due to insufficient clinical response ( 1 case in the sildenafil group and 7 in the placebo group) or other reasons ( 7 cases in the sildenafil group and 4 in the placebo group). Adverse events were registered in $82 \%$ of the patients treated with sildenafil and in $40 \%$ of the patients that took placebo. Of all these events, only 4 in each group were graded as severe. Table-4 shows the most frequent adverse events that were considered related to study drugs. Among patients treated with sildenafil, the most common adverse events were headache (11.4\% of the patients), vasodilation $(11.4 \%)$ and dyspepsia $(6.5 \%)$. Four patients had serious adverse events according to protocol definitions (cerebrovascular accident, pulmonary edema/heart failure, atrial fibrillation/arrhythmia and polytrauma); the former 3 events occurred in patients treated with sildenafil, and the latter occurred in a patient that was taking placebo. None of these events were deemed to be re- lated to the study drugs. The case of poly-trauma was secondary to a car accident, and this patient died during the study.

Table 4 - Adverse events occurring in $2 \%$ or more of patients (intent-to-treat sample, $N=120$ ).

\begin{tabular}{lrrrr}
\hline & \multicolumn{3}{c}{ N Patients $(\%)$} \\
Adverse Event & Sildenafil & & Placebo \\
& $(\mathrm{N}=61)$ & & $(\mathrm{N}=59)$ \\
\hline Vasodilation or & $8(13.1 \%)$ & 2 & $(3.4 \%)$ \\
$\quad$ facial flushing & $7(11.4 \%)$ & 2 & $(3.4 \%)$ \\
Headache & $6(9.8 \%)$ & 1 & $(1.7 \%)$ \\
Rhinitis & 4 & $(6.5 \%)$ & 0 & $(0 \%)$ \\
Dyspepsia & 2 & $(3.2 \%)$ & 1 & $(1.7 \%)$ \\
Dizziness & 2 & $(3.2 \%)$ & 1 & $(1.7 \%)$ \\
Abdominal pain & 2 & $(3.2 \%)$ & 0 & $(0 \%)$ \\
Paresthesia & 1 & $(1.6 \%)$ & 3 & $(5.1 \%)$ \\
Hypertension & 1 & $(1.6 \%)$ & 2 & $(3.4 \%)$ \\
Chest pain & 1 & $(1.6 \%)$ & 2 & $(3.4 \%)$ \\
Flu-like syndrome & 1 & $(1.6 \%)$ & 2 & $(3.4 \%)$ \\
Diarrhea & $35(57.3 \%)$ & 16 & $(27.1 \%)$ \\
Total & & & & \\
\hline
\end{tabular}




\section{Behavior of the Blood Pressure (BP)}

Figures-3 to 6 show patients' BP behavior during the 4 weeks of eligibility assessment and the 8 weeks of treatment, both in the supine (Figures-3 and 4) and seating (Figures-5 and 6) positions. There were no significant changes between the BP measurements when patients treated with sildenafil or placebo were compared. In both groups, there were progressive decreases in both systolic and diastolic BP readings during the study.

\section{COMMENTS}

Several organic and psychological factors interact to maintain a normal erectile function $(1,14)$. Penile erection is a hemodynamic event that depends on the relaxation of the smooth muscle cells of the trabeculae and arterioles of the corpora cavernosa. In response to sexual stimulation, non-adrenergic noncholinergic nerve fibers and arteriolar endothelial cells of the penis release nitric oxide (NO), a potent vasodilator that stimulates the activity of guanylate cyclase and leads to an increase in cyclic guanosine3',5'-monophosphate (cGMP). The ultimate effect is calcium depletion from the cytosolic space and cavernous smooth muscle relaxation. Phosphodiesterase 5 (PDE5), an enzyme that is present in the corpora cavernosa, inactivates cGMP, thus terminating NOcGMP-mediated smooth muscle relaxation. Inhibition of PDE5 enhances penile erection by preventing cGMP degradation (15). Sildenafil is a potent and selective inhibitor of PDE5 (16).

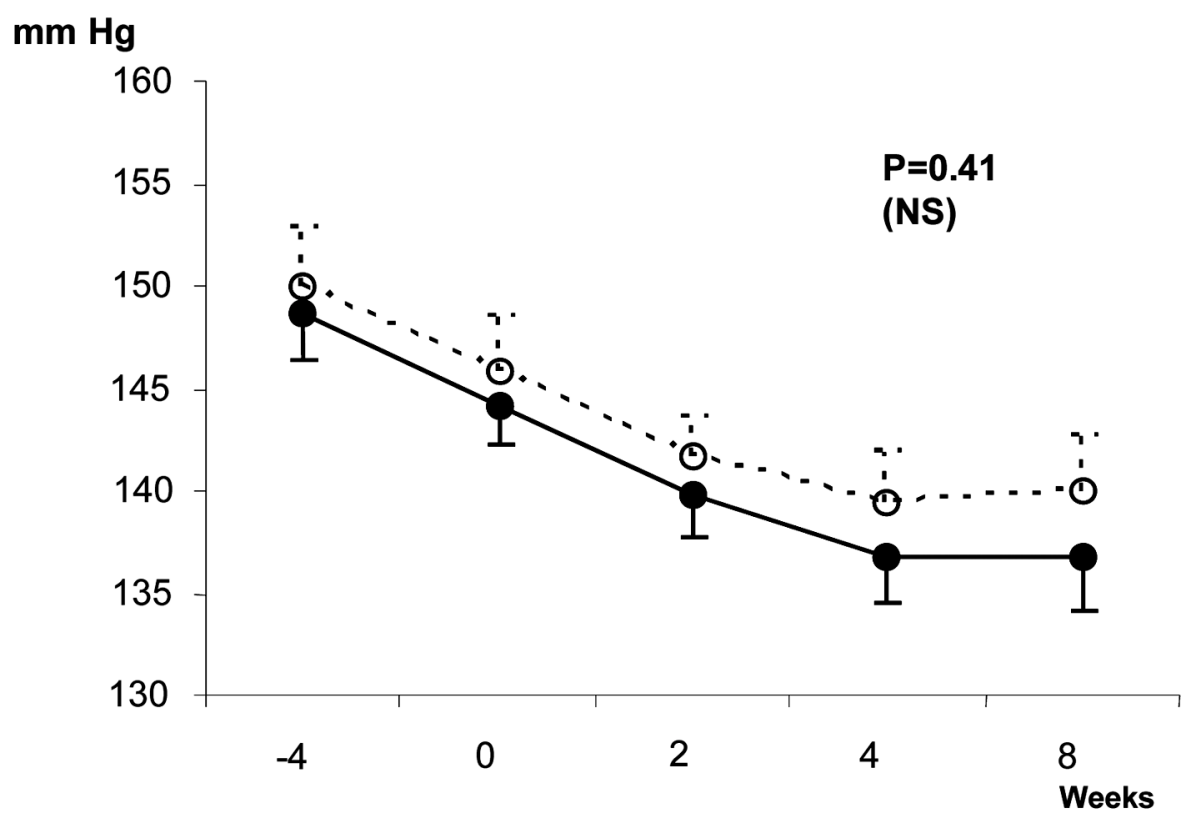

Figure 3 - Blood pressure (BP) behavior during the study. Systolic BP in the supine position. P values refer to the comparisons between sildenafil and placebo. NS = not significant. 


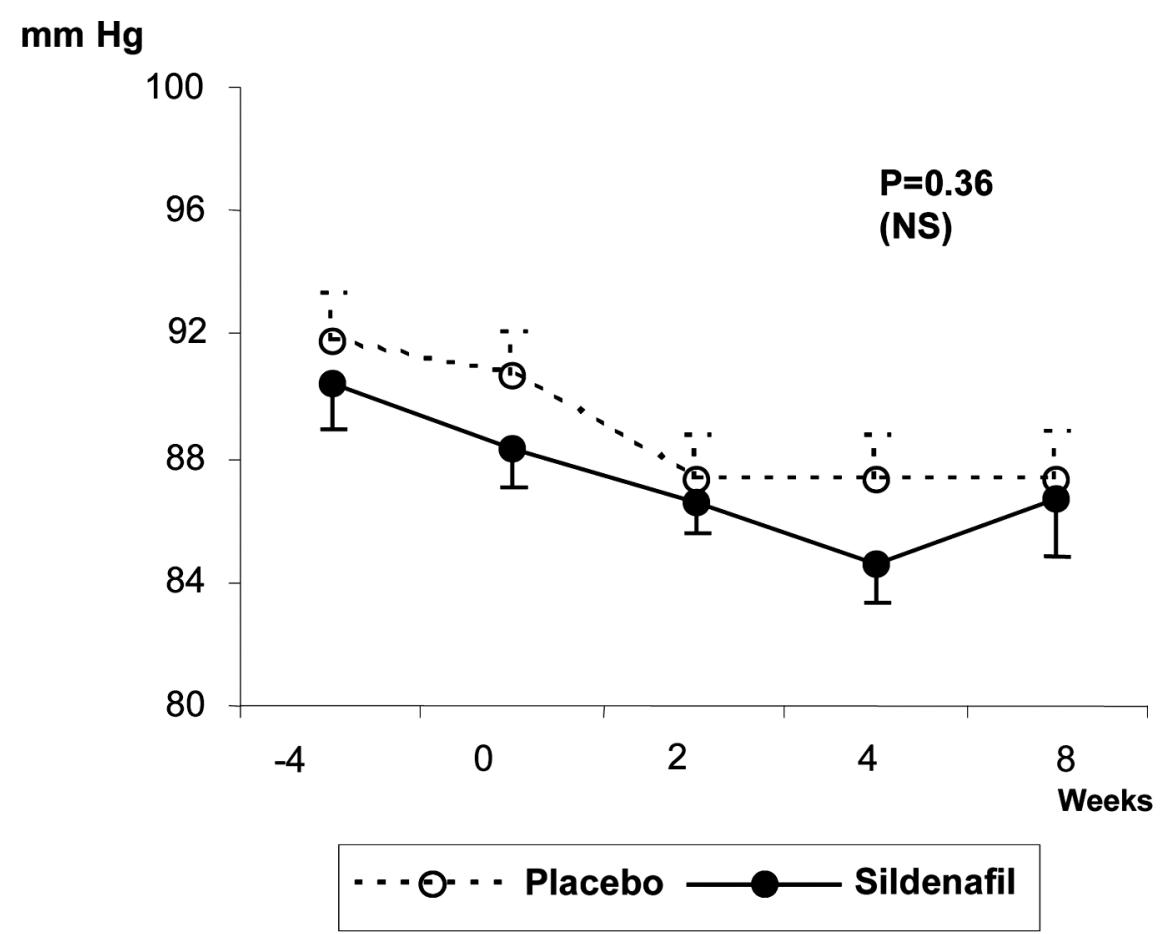

Figure 4 - Blood pressure (BP) behavior during the study. Diastolic BP in the supine position. P values refer to the comparisons between sildenafil and placebo. NS = not significant.

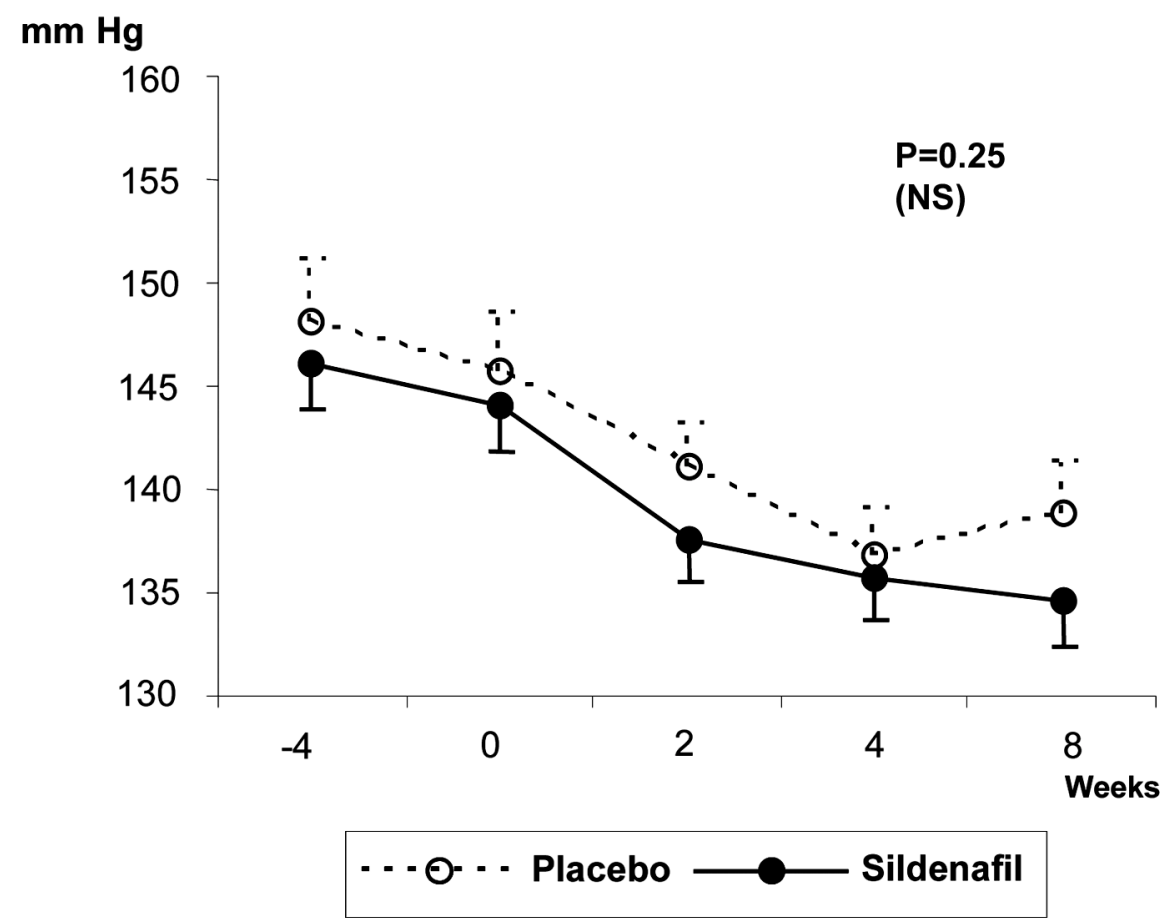

Figure 5 - Blood pressure (BP) behavior during the study. Systolic BP in sitting position. P values refer to the comparisons between sildenafil and placebo. NS = not significant. 


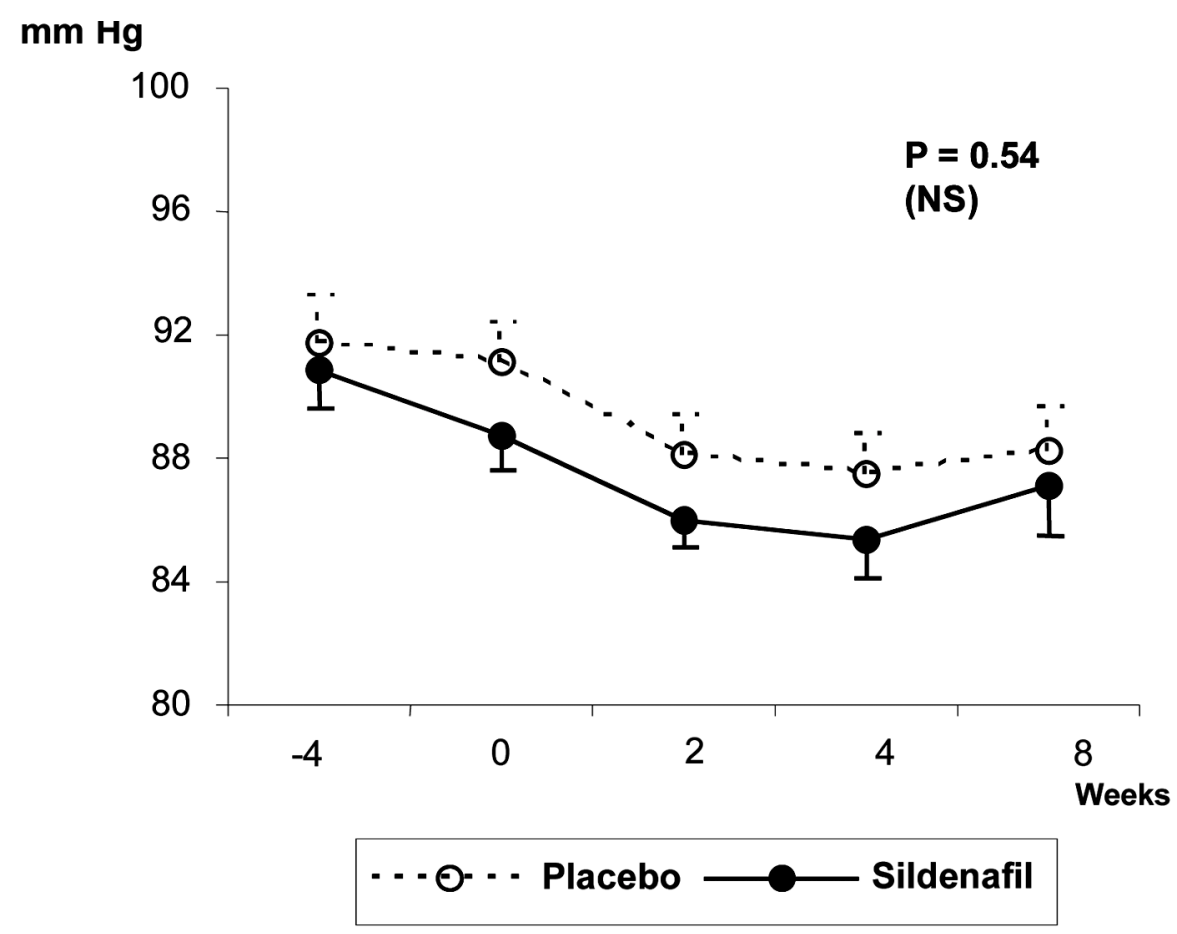

Figure 6 - Blood pressure (BP) behavior during the study. Diastolic BP in sitting position. P values refer to the comparisons between sildenafil and placebo. NS = not significant.

There is abundant evidence pointing to the relationship between ED and atherosclerosis and its risk factors. Abnormalities in blood flow to the penis, which are frequent in patients with atherosclerosis and diabetes mellitus, are a common factor underlying organic ED. Approximately $40 \%$ of patients with ED who are older than 50 years have associated atherosclerosis. It is also estimated that ED occurs in approximately $50 \%$ of patients with diabetes, regardless of the type; in these patients, the incidence of ED seems to correlate with age and the severity of diabetes $(17,18)$. Patients with conventional risk factors for atherosclerotic coronary artery disease, such as smoking, low levels of high-density lipoprotein cholesterol and diabetes, are at increased risk for developing ED (19).

Most adverse events reported in the clinical studies of sildenafil have been dose-dependent and secondary to vasodilation; among such events, headache, flushing and nasal congestion are the most fre- quent. The effects of sildenafil on BP have been well characterized (20-23). In physiological conditions, sildenafil may lead to a mild to moderate decrease in BP. In normotensive men, doses of $100 \mathrm{mg}$ of sildenafil may decrease systolic BP by up to $8-10 \mathrm{~mm}$ $\mathrm{Hg}$, and diastolic BP by up to 3-6 $\mathrm{mm} \mathrm{Hg} \mathrm{(21).} \mathrm{The}$ hypotensive effect of sildenafil may also be seen among patients with hypertension, although its magnitude may not be clinically significant in comparison to pretreatment BP levels $(22,23)$. The peak hypotensive effect of sildenafil typically occurs approximately one hour after ingestion, and coincides with peak plasma levels. In healthy men, the BP decreases induced by sildenafil return to pretreatment levels within 4 to 8 hours; these decreases are usually asymptomatic (20).

Some authors have attempted to investigate the safety of the concurrent administration of sildenafil and anti-hypertensive drugs. Most of the studies reported to date have looked at one anti-hy- 
pertensive agent used in isolation. Studies with diuretics, alpha-blockers, beta-blockers, ACE inhibitors, angiotensin II receptor antagonists, and calcium-channel blockers have shown that these agents may usually be given concurrently with sildenafil with no clinically significant hypotensive effect (22). Mild (2 to $4 \mathrm{~mm} \mathrm{Hg}$ ) decreases in systolic and diastolic BP have been seen among patients with hypertension who were on treatment with single anti-hypertensive drugs and who took sildenafil (24). In addition, the type and frequency of adverse events seen in such patients have not differed from those that are seen among patients who are not in treatment for hypertension $(24,25)$. Sildenafil does not seem to have pharmacodynamic interactions with anti-hypertensive drugs that act through NO-independent mechanisms $(23,25,26)$.

There is relatively little information in the literature regarding the use of sildenafil in patients with hypertension who are being treated with combinations of anti-hypertensive drugs (11). Kloner et al. have found no difference in the frequency of adverse events in patients taking sildenafil who were on treatment with one, two or three anti-hypertensive drugs. In that study, the concurrent use of sildenafil and multiple anti-hypertensive agents led to no apparent increase in the frequency or severity of angina, myocardial infarction or other serious cardiac events (27).

In the present study, the use of sildenafil significantly improved the erectile function of Brazilian men with hypertension who were under treatment with multiple anti-hypertensive drugs. As compared with patients who took a placebo, patients treated with sildenafil had significant improvements in their ability to achieve and maintain an erection. Secondary assessments confirmed the superiority of sildenafil that led to global improvements in $87 \%$ of the patients. This proportion of improvement is similar to that seen in other studies of sildenafil, including those in patients without hypertension. The present study also confirms that sildenafil produces no significant effect on sexual desire. Importantly, our study demonstrates the safety and tolerability of sildenafil in patients with hypertension who are under treatment with combinations of anti-hypertensive drugs. Treatment with sildenafil was well tolerated, and dose adjustments during the study possibly contributed to a reduction in the frequency of adverse events. As in other studies, headache, vasodilation and dyspepsia, typically of mild intensity, were the most frequent treatment-related adverse events. Interestingly, the effects of sildenafil on BP were not different from those produced by placebo.

\section{CONCLUSION}

In conclusion, our results indicate that sildenafil is efficacious, safe and well tolerated in the treatment of ED in patients with hypertension who are being treated with combinations of anti-hypertensive drugs.

$$
\begin{aligned}
& \text { Drs. Ari Timerman, João C. F. Braga and } \\
& \text { Marcus Malachias collaborated on the study. }
\end{aligned}
$$

\section{REFERENCES}

1. NIH Consensus Conference. Impotence. NIH Consensus Development Panel on Impotence. JAMA. 1993; 270: 83-90.

2. Rosen RC, Fisher WA, Eardley I, Niederberger C, Nadel A, Sand M, et al.: The multinational Men's Attitudes to Life Events and Sexuality (MALES) study: I. Prevalence of erectile dysfunction and related health concerns in the general population. Curr Med Res Opin. 2004; 20: 607-17.

3. Moreira ED Jr, Lobo CF, Diament A, Nicolosi A, Glasser DB: Incidence of erectile dysfunction in men 40 to 69 years old: results from a population-based cohort study in Brazil. Urology. 2003; 61: 431-6.

4. Mion D Jr, Nobre F, Kohlmann O, Jr, Machado CA, Gomes MAM, Amodeo C, et al.: IV Brazilian Guideline in Arterial Hypertension [in Portuguese]. (2002) Available at http://www.sbh.org.br/documentos/ index.asp (accessed 19 October 2004).

5. Seftel AD, Sun P, Swindle R: The prevalence of hypertension, hyperlipidemia, diabetes mellitus and depression in men with erectile dysfunction. J Urol. 2004; 171: 2341-5.

6. Feldman HA, Johannes CB, Derby CA, Kleinman KP, Mohr BA, Araujo AB, et al.: Erectile dysfunction and coronary risk factors: prospective results from the 
Massachusetts Male Aging Study. Prev Med. 2000; 30: 328-38.

7. Chew KK, Earle CM, Stuckey BG, Jamrozik K, Keogh EJ: Erectile dysfunction in general medicine practice: prevalence and clinical correlates. Int J Import Res. 2000; 12: 41-5.

8. Goldstein I, Lue TF, Padma-Nathan H, Rosen RC, Steers WD, Wicker PA: Oral sildenafil in the treatment of erectile dysfunction. Sildenafil Study Group. N Engl J Med. 1998; 338: 1397-404. Erratum in: N Engl J Med 1998; 339: 59.

9. Moore RA, Edwards JE, McQuay HJ: Sildenafil (Viagra) for erectile dysfunction: a meta-analysis of clinical trial reports. BMC Urol. 2002; 2: 6.

10. Glina S, Bertero E, Claro JA, Damiao R, Faria G, Fregonesi A, et al.: Efficacy and safety of flexible-dose oral sildenafil citrate (Viagra) in the treatment of erectile dysfunction in Brazilian and Mexican men. Int $\mathbf{J}$ Impot Res. 2002; 14 (Suppl 2): S27-S32.

11. Cheitlin MD, Hutter AM, Brindis RG, Ganz P, Kaul S, Russell RO Jr, et al.: Use of sildenafil (Viagra) in patients with cardiovascular disease. Technology and Practice Executive Committee. Circulation. 1999; 99: 168-77. Erratum in: Circulation 1999; 100: 2389.

12. Rosen RC, Riley A, Wagner G, Osterloh IH, Kirkpatrick J, Mishra A: The international index of erectile function (IIEF): a multidimensional scale for assessment of erectile dysfunction. Urology. 1997; 49: 822-30.

13. Lewis R, Bennett CJ, Borkon WD, Boykin WH, Althof SE, Stecher VJ, et al.: Patient and partner satisfaction with Viagra (sildenafil citrate) treatment as determined by the Erectile Dysfunction Inventory of Treatment Satisfaction Questionnaire. Urology. 2001; 57: 960-5.

14. Benet AE, Melman A: The epidemiology of erectile dysfunction. Urol Clin North Am. 1995; 22: 699-709.

15. Anderson KE, Wagner G: Physiology of penile erection. Physiol Rev. 1995; 75: 191-236.

16. Boolell M, Allen MJ, Ballard SA, Gepi-Attee S, Muirhead GJ, Naylor AM, et al.: Sildenafil: an orally active type 5 cyclic GMP-specific phosphodiesterase inhibitor for the treatment of penile erectile dysfunction. Int J Import Res. 1996; 8: 47-52.

17. Rubin A, Babbott D: Impotence and diabetes mellitus. JAMA. 1958; 168: 498-500.

18. McCulloch DK, Campbell IW, Wu FC, Prescott RJ: The prevalence of diabetic impotence. Diabetologia. 1980; 18: 279-83.

19. Feldman HA, Goldstein I, Hatzichristou DG, Krane RJ, McKinlay JB: Impotence and its medical and psy- chosocial correlates: results of Massachusetts Male Aging Study. J Urol. 1994; 151: 54-61.

20. Jackson G, Benjamin N, Jackson N, Allen MJ: Effects of sildenafil citrate on human hemodynamics. Am J Cardiol. 1999; 83: 13C-20C.

21. Morales A, Gingell C, Collins M, Wicker PA, Osterloh $\mathrm{IH}$ : Clinical safety of oral sildenafil citrate (Viagra) in the treatment of erectile dysfunction. Int J Import Res. 1998; 10: 69-73; discussion 73-4.

22. Zusman RM, Morales A, Glasser DB, Osterloh IH: Overall cardiovascular profile of sildenafil citrate. Am J Cardiol. 1999; 83: 35C-44C.

23. Kloner RA, Zusman RM: Cardiovascular effects of sildenafil citrate and recommendations for its use. Am J Cardiol. 1999; 84: 11N-17N.

24. Zusman RM, Prisant LM, Brown MJ: Effect of sildenafil citrate on blood pressure and heart rate in men with erectile dysfunction taking concomitant antihypertensive medication. Sildenafil Study Group. Am J Hypertens. 2000; 18: 1865-9.

25. Kloner RA, Brown M, Prisant LM, Collins M: Effect of sildenafil in patients with erectile dysfunction taking antihypertensive therapy. Sildenafil Study Group. Am J Hypertens. 2001; 14: 70-3.

26. Webb DJ, Freestone S, Allen MJ, Muirhead GJ: Sildenafil citrate and blood-pressure-lowering drugs: results of drug interaction studies with an organic nitrate and a calcium antagonist. Am J Cardiol. 1999; 83: 21C-28C.

27. Kloner RA, Brown M, Sildenafil Study Group: Safety of sildenafil citrate in men with erectile dysfunction taking multiple antihypertensive agents. Am J Hypertens. 1999; 12: 37A.

\section{DISCLAIMER}

Pfizer, Inc. supported the study.

Received: November 24, 2004 Accepted after revision: May 16, 2005

\section{Correspondence address:}

Dr. Denilson Campos Albuquerque

Rua Voluntários da Pátria, 445 / 1402

Rio de Janeiro, RJ, 22270-000, Brazil

Fax: + 5521 2266-2606

E-mail: albuquerque@doctor.com 


\section{EDITORIAL COMMENT}

Many researchers have suggested that erectile dysfunction (ED) co-exists with other diseases because they share common risk factors. Based on published studies, ED has been found in patients with hypertension, hyperlipidemia, diabetes mellitus, depression, ischemic heart disease, coronary heart disease, peripheral vascular disease etc. However, published information on the prevalence of these concurrent diseases in men with ED has been limited in terms of the number or sample size of the studies.

ED is common among men taking anti-hypertensive drugs to control blood pressure. Actually, ED could be caused either by hypertension itself, by the anti-hypertensive drugs or by the combination of both.

The impact of ED on the patient's quality of life is much more important than the impact of hypertension itself. Because of this, any well conducted study to evaluate the efficacy and safety of the 5 PDE inhibitors is very welcome.

Although this is a sponsored study, it was well designed and it is important for to emphasize that even patients receiving multiple anti-hypertensive drugs can be treated with 5 PDE inhibitors. The results found in the present study are quite promising. Otherwise, perhaps a more reasonable success rate in such patients (presenting cardiovascular diseases) would be around $70 \%$ (1).

Furthermore, despite the knowledge that these drugs are safe even in critical patients and in doses as high as $400 \mathrm{mg} 4$ times a day (2), the expected side effects in this population seems to reach $40 \%$ (1).

In any event, the message of the study is that 5 PDE inhibitors are safe and present a high success rate even in critical patients with hypertension who are being treated with multiple anti-hypertensive drugs.

\section{REFERENCES}

1. Pickering TG, Shepherd AM, Puddey I, Glasser DB, Orazem J, Sherman N, et al.: Sildenafil citrate for erectile dysfunction in men receiving multiple antihypertensive agents: a randomized controlled trial. Am J Hypertens. 2004; 17: 1135-42.

2. Paez RP, Araújo WF, Hossne Jr NA, Neves AL, Vargas GF, Aguiar LF, et al.: Sildenafil improves right ventricular function in a cardiac transplant recipient. Arq Bras Cardiol. 2005; 84: 176-8.

Dr. Joaquim de Almeida Claro Division of Urology, Section of Andrology Federal University of Sao Paulo, UNIFESP

Sao Paulo, SP, Brazil

\section{EDITORIAL COMMENT}

This well-designed study and clearly written paper is another important Brazilian contribution to the international urological literature. Previously, there was scant information on the effects of sildenafil in hypertensive patients who are taking multiple antihypertensive agents. This report demonstrates that sildenafil is efficacious and safe for the treatment of erectile dysfunction (ED) in men taking various combinations of antihypertensive drugs. The report also demonstrates that despite its vasodilatory action, sildenafil does not complicate treatment or interfere with control of hypertension in these men. 
This is important information because it might have been predicted that men with hypertension severe enough to require multiple antihypertensive agents would have more advanced ED, which is more difficult to treat successfully. In fact, analyzing the data presented in the tables, the pre-treatment scores on the erectile function domain (questions 1-5 and 15) of the International Index of Erectile Function (IIEF) were 12.26 and 12.93 in the placebo and sildenafil groups. These pre-treatment scores are slightly lower than the pre-treatment scores seen in most other sildenafil clinical trials, suggesting that the men in this study might have had slightly more severe ED than men in other studies. The post-treatment score on the erectile function domain in the placebo group in this study rose only to 14.75 , demonstrating a mild placebo effect, while the post-treatment score in the sildenafil group rose to 24.14 , clearly demonstrating the efficacy of sildenafil. The score of 24.14 is somewhat higher than has been reported in most other sildenafil clinical trials, showing that sildenafil is as effective in men using multiple antihypertensive agent combinations as in many other groups of men with ED.

The authors are to be congratulated for completing an excellent study that fills one of the gaps in the international literature on sexual medicine.

Dr. Ira D. Sharlip

Clinical Professor of Urology University of California San Francisco San Francisco, California, USA 